\title{
Glioma Recurrence following Surgery: Peritumoral or Perilesional?
}

\author{
Boudewijn van der Sanden ${ }^{1+}$, David Ratel ${ }^{2}$, François Berger ${ }^{1 \dagger}$ and Didier Wion ${ }^{1 * t}$ \\ ${ }^{1}$ INSERM UA01, Clinatec, Institut E.J. Safra, CEA, Grenoble, France, ${ }^{2}$ Clinatec, Institut E.J. Safra, CEA, Grenoble, France
}

Keywords: glioma, surgery injury, microenvironment, inflammation, recurrence, paradigm shift

\section{BACKGROUND}

In comparison to other cancers, gliomas are locally invasive cancers that seldom metastasize. Glioma cells infiltrate brain parenchyma up to several centimeters from the tumor core. Therefore, their recurrence occurs at the margin of tumor resection in about $90 \%$ of patients (1). Significant effort is put into analyzing peritumoral regions to understand the mechanisms of glioma recurrence after surgery (1-4). Such studies are done on peritumoral biopsies collected either before or during surgery. This comment seems incidental but is critical.

OPEN ACCESS

Edited by:

Roger Stupp,

University of Zurich Hospital,

Switzerland

Reviewed by:

Philippe Schucht,

Inselspital, Switzerland

${ }^{*}$ Correspondence:

Didier Wion

didier.wion@ujf-grenoble.fr

tPresent address:

Boudewijn van der Sanden,

François Berger and Didier Wion,

INSERM UMR1205, bâtiment

modulaire 40-23, CEA,

Grenoble, France

Specialty section:

This article was submitted to

Neuro-Oncology,

a section of the journal

Frontiers in Neurology

Received: 06 November 2015

Accepted: 21 March 2016

Published: 31 March 2016

Citation:

van der Sanden $B$, Ratel $D$, Berger $F$ and Wion D (2016) Glioma

Recurrence following Surgery:

Peritumoral or Perilesional?

Front. Neurol. 7:52.

doi: 10.3389/fneur.2016.00052

\section{SURGICAL BRAIN INJURY RESHAPES THE PERITUMORAL LANDSCAPE}

A critical overlooked point in neurooncology is that brain surgery triggers a wound-healinginflammatory process in the resection margins where residual glioma cells are. Glioma resection is lesional, and it generates dramatic rearrangements in the peritumoral brain region. The protumorigenic role of wounds and the vicious connection between inflammation and cancer have long been established in other tissues $(5,6)$. Regarding brain tissue, we already know that in the minutes following cortical and parenchymal incisions, surgical brain injury (SBI) induces (i) a burst of glutamate and ATP, (ii) the release of mutagenic reactive oxygen species, and (iii) an influx of blood clotting factors and serum components $(7,8)$. Fibroblasts, mesenchymal stem cells, and other blood-borne cells, including inflammatory cells, also invade the resection margin $(7,8)$. This in turn leads to a further release of cytokines and growth factors. Small ischemic areas around the resection cavity, which are an important driver for malignant progression, are also observed $(9,10)$. Hallmarks of this perilesional region include inflammation, angiogenesis, glial cell proliferation, reactive gliosis, and fibrosis $(7,8)$. Indeed, SBI reshapes the peritumoral landscape into a protumorigenic environment.

\section{CONCLUSION}

Peritumoral biopsies collected before or during surgery are not representative of the SBI-induced protumorigenic microenvironment. Hence, critical information is missing to understand and prevent tumor recurrence. Personalized medicine and targeted therapies must integrate new technologies to improve our understanding of the SBI zone. Considering the resection margins as peritumoral or as perilesional is more than a simple matter of vocabulary. It is a necessary paradigm shift to understand and treat glioma recurrence after surgery.

\section{AUTHOR CONTRIBUTIONS}

All authors listed, have made substantial, direct, and intellectual contribution to the work, and approved it for publication. 


\section{REFERENCES}

1. Lemée J-M, Clavreul A, Menei P. Intratumoral heterogeneity in glioblastoma: don't forget the peritumoral brain zone. Neuro Oncol (2015) 17:1322-32. doi:10.1093/neuonc/nov119

2. Gill BJ, Pisapia DJ, Malone HR, Goldstein H, Lei L, Sonabend A, et al. MRIlocalized biopsies reveal subtype-specific differences in molecular and cellular composition at the margins of glioblastoma. Proc Natl Acad Sci U S A (2014) 111:12550-5. doi:10.1073/pnas.1405839111

3. Fazi B, Felsani A, Grassi L, Moles A, D’Andrea D, Toschi N, et al. The transcriptome and miRNome profiling of glioblastoma tissues and peritumoral regions highlights molecular pathways shared by tumors and surrounding areas and reveals differences between short-term and long-term survivors. Oncotarget (2015) 6(26):22526-52. doi:10.18632/oncotarget.4151

4. Aubry M, de Tayrac M, Etcheverry A, Clavreul A, Saikali S, Menei P, et al. From the core to beyond the margin: a genomic picture of glioblastoma intratumor heterogeneity. Oncotarget (2015) 6:12094-109. doi:10.18632/ oncotarget.3297

5. Kuraishy A, Karin M, Grivennikov SI. Tumor promotion via injury- and death-induced inflammation. Immunity (2011) 35:467-77. doi:10.1016/j. immuni.2011.09.006

6. Grivennikov SI, Karin M. Inflammation and oncogenesis: a vicious connection. Curr Opin Genet Dev (2010) 20:65-71. doi:10.1016/j.gde.2009. 11.004
7. Burda JE, Sofroniew MV. Reactive gliosis and the multicellular response to CNS damage and disease. Neuron (2014) 81:229-48. doi:10.1016/j. neuron.2013.12.034

8. Liu J-M, Mao B-Y, Hong S, Liu Y-H, Wang X-J. The postoperative brain tumour stem cell (BTSC) niche and cancer recurrence. Adv Ther (2008) 25:389-98. doi:10.1007/s12325-008-0050-x

9. Gempt J, Förschler A, Buchmann N, Pape H, Ryang Y-M, Krieg SM, et al. Postoperative ischemic changes following resection of newly diagnosed and recurrent gliomas and their clinical relevance. J Neurosurg (2013) 118:801-8 doi:10.3171/2012.12.JNS12125

10. Yang L, Lin C, Wang L, Guo H, Wang X. Hypoxia and hypoxia-inducible factors in glioblastoma multiforme progression and therapeutic implications. Exp Cell Res (2012) 318:2417-26. doi:10.1016/j.yexcr.2012.07.017

Conflict of Interest Statement: The authors declare that the research was conducted in the absence of any commercial or financial relationships that could be construed as a potential conflict of interest.

Copyright (c) 2016 van der Sanden, Ratel, Berger and Wion. This is an open-access article distributed under the terms of the Creative Commons Attribution License (CC $B Y)$. The use, distribution or reproduction in other forums is permitted, provided the original author(s) or licensor are credited and that the original publication in this journal is cited, in accordance with accepted academic practice. No use, distribution or reproduction is permitted which does not comply with these terms. 